\title{
Inferior ST-Elevation Myocardial Infarction Presenting When Urgent Primary Percutaneous Coronary Intervention Is Unavailable: Should We Adhere to Current Guidelines?
}

\author{
Yochai Birnbaum ${ }^{1}$ (D) Glenn N. Levine ${ }^{1,2} \cdot$ John French $^{3} \cdot$ Juan Carlos Kaski $^{4} \cdot$ Dan Atar $^{5} \cdot$ Mahboob Alam $^{1}$. \\ David Hasdai $^{6} \cdot$ Hani Jneid ${ }^{1,2} \cdot$ Barry F. Uretsky $^{7}$
}

Accepted: 13 July 2020 / Published online: 15 July 2020

(C) Springer Science+Business Media, LLC, part of Springer Nature 2020

\begin{abstract}
The pivotal studies that led to the recommendations for emergent reperfusion therapy for ST-elevation myocardial infarction (STEMI) were conducted for the most part over 25 years ago. At that time, contemporary standard treatments including aspirin, statin, and even anticoagulation were not commonly used. The 2013 American College of Cardiology Foundation (ACCF)/ American Heart Association (AHA) guidelines and the 2017 European Society of Cardiology guidelines give a class I recommendation (with the level of evidence A) for primary percutaneous coronary intervention (pPCI) in patients with STEMI and ischemic symptoms of less than $12 \mathrm{~h}$. However, if the patient presents to a hospital without pPCI capacity, and it is anticipated that pPCI cannot be performed within 120 min of first medical contact, fibrinolytic therapy is indicated (if there are no contraindications) (class I indication, level of evidence A). Our review of the pertinent literature shows that the current recommendation for inferior STEMI is based on the level of evidence lower than A. We can consider level B even C, supporting the recommendation for fibrinolytic therapy if pPCI is not available for inferior STEMI.
\end{abstract}

Keywords Fibrinolytic therapy $\cdot$ Guidelines $\cdot$ Reperfusion therapy $\cdot$ ST-elevation myocardial infarction

In the book "Sapiens, a brief history of humankind, Yuval Noah Harari discusses the Scientific Revolution and the importance of the concept of "Ignoramus": The willingness to

Yochai Birnbaum

ybirnbau@bcm.edu

1 The Department of Medicine, The Section of Cardiology, Baylor College of Medicine, One Baylor Plaza, MS BCM620, Houston, TX 77030, USA

2 The Section of Cardiology, Michael E. DeBakey VA Medical Center, Houston, TX, USA

3 Department of Cardiology, Liverpool Hospital, Universities of New South Wales \& Western Sydney, Sydney, Australia

4 Molecular and Clinical Sciences Research Institute, St George's, University of London, London, UK

5 Department of Cardiology, Oslo University Hospital Ulleval, Oslo, Norway, and Institute of Clinical Sciences, University of Oslo, Oslo, Norway

6 Rabin Medical Center, Tel Aviv University, Petah Tikva, Israel

7 Central Arkansas Veterans Health System and the University of Arkansas for Medical Sciences, Little Rock, AR, USA admit ignorance: Modern science is based on the Latin injunction Ignoramus - "we do not know." It assumes that we do not know everything. Even more critically, it accepts that the things that we think we know could be proven wrong as we gain more knowledge. No concept, idea, or theory is sacred and beyond challenge" [1]. We have to accept that as our knowledge accumulates, old data, paradigms, and practice guidelines could become irrelevant or insufficient.

The clinician is encouraged to follow clinical guidelines. In fact, following guidelines is considered a measure of "quality of care". However, we should be reminded that guidelines are simply that and not rigid rules. They intend to assist us in the management of the patient who fits the guideline criteria and is not intended to cover all possible clinical scenarios and combinations. Ultimately, the clinician must decide the best treatment for an individual patient, based on knowing the guidelines and (as much as possible), the actual data, and especially the pivotal clinical trials that led to the guideline recommendations. We need to acknowledge that as data accumulate, additional therapies and modalities become standard of care and the old studies might become less relevant to current practice. 
Pivotal studies that led to recommendations for emergent reperfusion therapy for ST-elevation myocardial infarction (STEMI) were conducted for the most part over 25 years ago. At that time, contemporary standard treatments including aspirin, statin, and even anticoagulation were not commonly used. In addition, coronary angiography after fibrinolytic therapy was not routinely performed either prior to rescue PCI or during hospitalization and, if so, was almost invariably via femoral access. There was a debate on whether fibrinolytic therapy should be given to all comers with suspected myocardial infarction or only to certain subgroups. This uncertainty was due in part because electrocardiographic criteria for trial entry varied [2] and not all trials limited inclusion to patients with ST-segment elevation [2]. In that regard, there was a question of whether fibrinolytic therapy is beneficial in patients with inferior myocardial infarction. Subsequently, when primary percutaneous coronary interventions (pPCI) largely replaced fibrinolytic therapy, this question was essentially "swept under the rug," as pPCI was shown to be more efficacious and safer than fibrinolytic therapy [3, 4]. However, in cases where pPCI is not feasible, the issue of the value of fibrinolytic therapy in inferior STEMI may still be relevant, as illustrated in the following case.

\section{Two Hypothetical Patients Are Described to Illustrate the Topic}

\section{Hypothetical Case 1}

A 76-year-old woman presents with 3-4 h of chest pain to a non-pPCI-capable hospital in the middle of a snowstorm. She has a history of gastrointestinal bleeding 5 years prior after taking the nonsteroidal anti-inflammatory drug for knee pain. However, she has not experienced any bleeding or heartburn since. Blood pressure is $130 / 90 \mathrm{mmHg}$ and heart rate $60 \mathrm{bpm}$. Physical examination is unremarkable. ECG shows sinus rhythm at $60 \mathrm{bpm}$; ST elevation in the inferior leads with reciprocal ST depression and T wave inversion in I and aVL (Fig. 1) compatible with inferior STEMI.

According to current guidelines, chewable aspirin and clopidogrel should be administered [4]. Both European and American guidelines recommend transfer to a pPCI-capable facility if it can be performed within $120 \mathrm{~min}[3,4]$. There is, however, a raging snowstorm. Transporting the patient is considered unsafe, and the expected arrival time to the pPCI-capable facility is estimated to be greater than $120 \mathrm{~min}$ (could take a few days).

\section{Hypothetical Case 2}

A 77-year-old man presents with $5 \mathrm{~h}$ of chest pain to a tertiary hospital with an on-site catheterization laboratory. He reports having fever malaise and cough for the last few days. He is hemodynamically stable, and ECG shows sinus rhythm at $72 \mathrm{bpm}, \mathrm{ST}$ elevation in the inferior leads. Due to the current COVID-19 pandemic, the hospital decided to use intravenous thrombolytic therapy instead of pPCI as a policy to minimize exposure, especially as the patient is hemodynamically stable and could have COVID-19 infection.

The 2013 American College of Cardiology Foundation (ACCF)/American Heart Association (AHA) guidelines and the 2017 European Society of Cardiology guidelines give a class I recommendation (with the level of evidence A) for pPCI in patients with STEMI and ischemic symptoms of less than $12 \mathrm{~h}[3,4]$. However, if the patient presents to a hospital without pPCI capacity, and it is anticipated that pPCI cannot be performed within 120 min of first medical contact, fibrinolytic therapy is recommended (if there are no contraindications) (class I indication, level of evidence A) [3, 4]. Remote history of gastrointestinal bleeding without active peptic ulcer is not considered a contraindication for thrombolytic therapy [3].

Whether or not the patient receives thrombolytic therapy, the patient should be transferred to a hospital with PCI facility when transportation becomes available, unless the patient is completely asymptomatic and more than $48 \mathrm{~h}$ passed from symptoms' onset [4].

\section{Discussion}

By providing a critical appraisal of the available knowledge base, we are questioning whether there is truly a level of evidence A for fibrinolytic therapy in inferior STEMI. The following studies provide evidence that underpins the current guideline recommendations for treatment of inferior STEMI:

Several randomized trials have compared outcomes of fibrinolytic therapy vs. no reperfusion therapy in patients presenting with suspected myocardial infarction (see below).
Fig. 1 Presenting ECG showing sinus rhythm $\sim 60 \mathrm{bpm}$ with ST elevation in the inferior leads and reciprocal ST depression in I and aVL

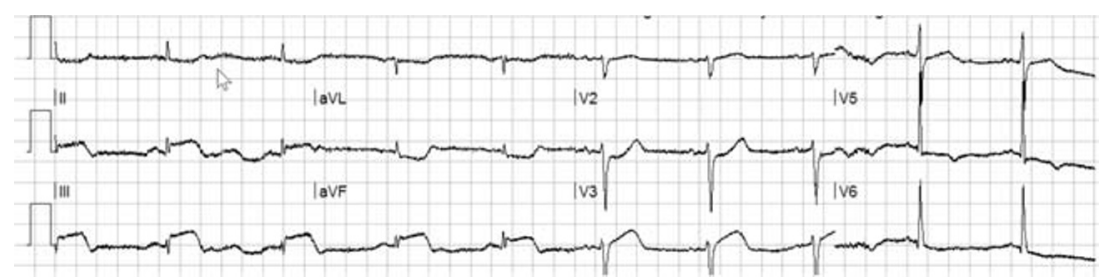


Extrapolation from these early studies to our current practice is problematic, insofar as the use of aspirin, $\mathrm{P} 2 \mathrm{Y}_{12}$ inhibitors, anticoagulation, beta-blockers, and statins was not routine at the time these studies were conducted. In the Gruppo Italiano per lo Studio della Streptochinasi nell'Infarto Miocardico (GISSI) trial, only $13-14.7 \%$ of the 11,806 enrolled patients received anti-platelet agents and $8.3 \%$ beta-blockers [5]. Among patients presenting within $12 \mathrm{~h}$ of symptom onset, streptokinase significantly reduced in-hospital mortality in anterior, but not inferior, STEMI [5]. The Second International Study of Infarct Survival (ISIS-2) randomized 17,187 patients within $24 \mathrm{~h}$ of onset of symptoms to streptokinase versus placebo and aspirin versus placebo [6]. Streptokinase reduced mortality in patients with anterior STEMI, but only produced a trend toward reduced mortality in patients with inferior STEMI. Furthermore, the beneficial effect of streptokinase was time dependent [6]. There is no report on the interaction between time and efficacy among the subgroup with inferior STEMI. Moreover, the study compared the overall effects of streptokinase versus placebo among the groups that received or did not receive aspirin. There is no comparison between the aspirin alone and streptokinase + aspirin treatments in inferior STEMI [6]. In this study, aspirin alone had the same effect as streptokinase on mortality and the effect of the combination was greater than aspirin alone or streptokinase alone.

The Urochinasi per via Sistemica nell'Infarto Miocardico (USIM) study reported increased mortality with urokinase in patients with inferior myocardial infarction (5.81\% vs. $3.20 \%$; $p=0.04$ ); however, only a quarter of the patients received anti-platelet therapy and 9-10\% received beta-blockers [7].

The Intravenous Streptokinase in Acute Myocardial Infarction (ISAM) trial [8], the APSAC Intervention Mortality Study (AIMS) [9], the Anglo-Scandinavian Study of Early Thrombolysis (ASSET) trial [10], the Estudio Multicéntrico Estreptoquinasa Repúblicas de América del Sur (EMERAS) trial [11], and the Late Assessment of Thrombolytic Efficacy (LATE) study [12] did not report on patient subgroup analysis based on infarct location or on concomitant use of other medications so the value of the use of fibrinolytic therapy in inferior STEMI cannot be ascertained.

The abovementioned earliest trials, that included more than 1000 patients per trial, were summarized by the Fibrinolytic Therapy Trialists Collaborative Group in 1994 [13]. Subgroup analysis showed that fibrinolytic therapy reduced 35-day mortality among patients with ST elevation in the anterior leads or "other" leads but failed to reach statistical significance among patients with ST elevation in the inferior leads (11\% proportional reduction; $95 \% \mathrm{CI}-24 \%$ to $+5 \% ; p=0.08)$ [13]. Personal communication from the FTT collaborative group that is quoted by a 1995 letter to the editor suggested that mortality was reduced by $13 \%$ from 8.1 to $7.1 \%$ (95\% CI $24 \%$ to $0 \%$ reduction for patients with inferior infarction randomized within $12 \mathrm{~h}$ of onset of symptoms), while the reduction in mortality was $14 \%$ from 7.6 to $6.6 \%(95 \% \mathrm{CI}$

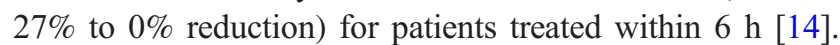
However, this analysis has not been directly published and was not part of the primary or secondary endpoints analysis and, thus, should be considered only as hypothesis generating. No other endpoints, such as heart failure, are provided. One later study and a review did not report on outcomes of the subgroup with inferior STEMI separately $[15,16]$.

The studies that reported on outcomes of patients with inferior infarct used non-fibrin-specific agents (streptokinase or urokinase), while later studies have shown the advantage of fibrin-specific agents (tenecteplase (TNK), tissue plasminogen activator (tPA), or single-strand PA (reteplase)) [4]. These latter studies did not tease out outcomes of inferior vs anterior STEMIs. According to the guidelines, a half-dose of TNK-tPA should be considered in patients older than 75 years [4]; this dose has not been tested versus no reperfusion therapy in patients with inferior STEMI. Moreover, we do not have sufficient data from randomized trials for the effects of fibrinspecific agents on top of aspirin loading (and clopidogrel), as they are now considered standard of care [4].

Guidelines specify that level A evidence or "estimate of certainty of treatment effect A" should be based on either data derived from multiple randomized clinical trials or metaanalyses [3, 4]. Level $\mathrm{B}$ is based on evidence from a single randomized trial or nonrandomized trial, whereas level $\mathrm{C}$ is based only on expert opinion, case studies, or registries [3, 4]. Thus, based on these definitions, the level of evidence supporting fibrinolytic therapy for inferior STEMI should, in our opinion, be downgraded to C, LD (limited data), or EO (expert opinion).

In all comer STEMIs, i.e., combining anterior, lateral, and inferior locations, pPCI is associated with reduced mortality compared with fibrinolytic therapy, if pPCI can be performed within $120 \mathrm{~min}$ of first medical encounter [17-19]. If the delay is $>120 \mathrm{~min}$, no beneficial effects of pPCI over fibrinolytic therapy have been observed [17-19]. However, most of the studies comparing fibrinolytic therapy to primary angioplasty in STEMI did not report on outcomes of inferior STEMI separately [20-28]. Although the GUSTO IIb [22] and the Danish Multicenter Randomized Study on Fibrinolytic Therapy versus Acute Coronary Angioplasty in Acute Myocardial Infarction (DANAMI-2) [29] reported similar advantage of pPCI over fibrinolytic therapy in patients with anterior and non-anterior STEMI, they did not specifically analyze inferior STEMI. Also, those patients randomized to fibrinolysis had a very low rescue PCI rate of $2-3 \%$ in the DANAMI-2 study, whereas in STREAM rescue PCI was $\sim 30 \%$, questioning the applicability DANAMI-2 to current practice. The Combined Abciximab REteplase Stent Study in Acute Myocardial Infarction (CARESS-in-AMI), on the other hand, did report the advantage of pPCI over fibrinolytic therapy in patients with inferior STEMI [30]. However, in the Strategic 
Table 1 Definitions of the levels of Estimate of Certainty (Precision) of Treatment Effect. 2013 ACCF/AHA STEMI Guidelines [3]

Level A: Multiple populations evaluated. Data derived from multiple randomized clinical trials or meta-analyses.

Level B: Limited populations evaluated. Data derived from a single randomized trial or nonrandomized studies.

Level C: Very limited populations evaluated. Only consensus opinion of experts, case studies, or standard of care.

Definitions of the Levels of Evidence. 2017 ESC STEMI Guidelines [4]

Level A: Data derived from multiple randomized clinical trials or meta-analyses.

Level B: Data derived from a single randomized clinical trial or large nonrandomized studies.

Level C: Consensus of opinion of experts and/or small studies, retrospective studies, registries.

Reperfusion Early after Myocardial Infarction (STREAM) study, the relative risk of the primary end point (death from any cause, shock, congestive heart failure, or reinfarction up to 30 days) favored fibrinolysis over pPCI for patients with inferior STEMI and was neutral for anterior STEMI [17]. Moreover, Dobrzycki et al. found no advantage for transfer for pPCI over fibrinolysis in patients arriving at hospitals without pPCI facility in patients with non-anterior STEMI [31]. Even a pooled analysis of 22 randomized clinical trials comparing pPCI and in-hospital fibrinolysis in STEMI patients showed that there was no significant advantage of pPCI on mortality in patients with non-anterior, in contrast to anterior, STEMI [32] Tables 1 and 2.

Compared with anterior wall STEMI, inferior STEMI has in general a more favorable prognosis [33]. However, certain patients (those with advanced atrioventricular block, right ventricular involvement, or precordial ST depression) are at higher risk. Moreover, certain ECG patterns, such as terminal QRS distortion in the leads with ST elevation [34], or ST depression mainly in V4-V6 [35-37] is associated with increased mortality. However, the efficacy of either fibrinolytic therapy or pPCI in reducing mortality in patients with these ECG patterns of inferior STEMI has not been studied. Therefore, recommending specific therapies for special ECG patterns of inferior STEMI cannot be based on scientific evidence.

One may argue that fibrinolysis added to "standard of care" provides additional benefits besides short-term mortality, such as limitation of infarct size, prevention of remodeling, and the development of heart failure or even long-term mortality benefit $[14,38]$. However, there is no direct evidence that these benefits overweight the potential risks associated with fibrinolysis in patients with inferior STEMI without high-risk features [39].

One may also argue that we need to concentrate on the primary endpoints of the original studies and any use of secondary endpoints or subgroup analyses should be considered only as hypothesis generating. Yet, using the exact same data, we accepted that fibrinolysis is not beneficial, and even considered harmful, in patients presenting without ST elevation or with isolated ST depression $[3,4]$.

In conclusion, the justification of reperfusion therapy for patients presenting with inferior STEMI is based on the overall benefit of reperfusion therapy in patients with STEMI; however, we do not have data to justify level of evidence A for fibrinolytic therapy in inferior STEMI. As reperfusion therapy for inferior STEMI (including fibrinolytic therapy if pPCI is not available) has become a "standard of care," it would be challenging (if not impossible) to conduct a randomized study comparing reperfusion therapy to no reperfusion therapy in these patients. Furthermore, the rationale to treat all STEMIs, the same is intuitively attractive.

Taken together, our review of the pertinent literature shows that the current recommendation for inferior STEMI is based on the level of evidence lower than A. We can consider level B (if we accepted the personal communication from the FTT

Table 2 Summary of the clinical trials evaluating the effects of fibrinolytic therapy versus no reperfusion therapy

\begin{tabular}{|c|c|c|c|c|c|c|c|}
\hline Study & Reference & $\begin{array}{l}\text { Total number } \\
\text { of patients }\end{array}$ & $\begin{array}{l}\text { Number of } \\
\text { patients with } \\
\text { inferior MI }\end{array}$ & Time frame & Inclusion criteria & Fibrinolytic agent & Finding \\
\hline GISSI & {$[4]$} & 11,712 & 4005 & $12 \mathrm{~h}$ & $\begin{array}{l}\text { Chest pain }+ \text { ST } \\
\quad \text { elevation or depression }\end{array}$ & Streptokinase & $\begin{array}{l}\text { Streptokinase significantly } \\
\text { reduced in-hospital mortality } \\
\text { in anterior, but not inferior MI. }\end{array}$ \\
\hline ISIS-2 & {$[5]$} & 17,187 & 4188 & $24 \mathrm{~h}$ & $\begin{array}{l}\text { Suspected MI. No } \\
\text { ECG criteria }\end{array}$ & Streptokinase & $\begin{array}{l}\text { Streptokinase reduced mortality in } \\
\text { patients with anterior, but MI, but } \\
\text { only produced a trend toward } \\
\text { reduced mortality in patients with } \\
\text { inferior MI. }\end{array}$ \\
\hline USIM & {$[6]$} & 2201 & 1041 & $4 \mathrm{~h}$ & $\begin{array}{l}\text { Chest pain }+ \text { ST } \\
\text { elevation or depression }\end{array}$ & Urokinase & $\begin{array}{l}\text { Increased mortality with urokinase in } \\
\text { patients with inferior MI. }\end{array}$ \\
\hline
\end{tabular}


collaborative group quoted in a letter [13]) or C. As such, clinicians should exert judgment in balancing the potential benefits versus risks in the individual patient presenting with suspected inferior STEMI when pPCI cannot be performed within $120 \mathrm{~min}$ of the first medical contact. As the use of fibrinolytic therapy is associated with increased risk of bleeding (intra-cranial hemorrhage in particular), the use of fibrinolysis for uncomplicated inferior STEMI without high-risk features (and with high potential bleeding risk) should probably not be a class I (benefits $\gg>>$ risks) indication. A class IIa (benefit>>risks, it is reasonable to perform) recommendation seems more appropriate. To be clear, we do not recommend against giving thrombolytic therapy in this case (class III indication), we just pointing out that per the definitions, set in the Guidelines documents does not support the current class I indication. We thus propose that any guideline revision in the future be more specific, stratifying the weight of its recommendations according to infarct location.

Due to the COVID-19 pandemic, many Medical Centers decided to use thrombolytic therapy instead of primary PCI for STEMI. This could be preferentially used for "low-risk" patients, including inferior STEMI. Thus, the question of the beneficial effects of thrombolytic therapy in uncomplicated inferior STEMI has become even more relevant.

Funding Information The study was funded by the John S. Dunn Chair in Cardiology Research and Education.

\section{Compliance with Ethical Standards}

Conflict of Interest The authors declare that they have no conflict of interest.

Ethical Statement N/A.

\section{References}

1. Harari YN. Sapiens: a brief history of humankind. New York: HarperCollins Publisher; 2015.

2. French JK, Williams BF, Hart HH, Wyatt S, Poole JE, Ingram C, et al. Prospective evaluation of eligibility for thrombolytic therapy in acute myocardial infarction. BMJ. 1996;312(7047):1637-41. https://doi.org/10.1136/bmj.312.7047.1637.

3. O'Gara PT, Kushner FG, Ascheim DD, Casey DE Jr, Chung MK, de Lemos JA, et al. 2013 ACCF/AHA guideline for the management of ST-elevation myocardial infarction: a report of the American College of Cardiology Foundation/American Heart Association Task Force on Practice Guidelines. Circulation. 2013;127(4):e362-425. https://doi.org/10.1161/CIR. 0b013e3182742cf6.

4. Ibanez B, James S, Agewall S, Antunes MJ, Bucciarelli-Ducci C, Bueno H, et al. 2017 ESC Guidelines for the management of acute myocardial infarction in patients presenting with ST-segment elevation: the Task Force for the management of acute myocardial infarction in patients presenting with ST-segment elevation of the
European Society of Cardiology (ESC). Eur Heart J. 2018;39(2): 119-77. https://doi.org/10.1093/eurheartj/ehx393.

5. Effectiveness of intravenous thrombolytic treatment in acute myocardial infarction. Gruppo Italiano per lo Studio della Streptochinasi nell'Infarto Miocardico (GISSI). Lancet. 1986;1(8478):397-402.

6. Randomised trial of intravenous streptokinase, oral aspirin, both, or neither among 17,187 cases of suspected acute myocardial infarction: ISIS-2. ISIS-2 (Second International Study of Infarct Survival) Collaborative Group. Lancet. 1988;2(8607):349-60.

7. Rossi P, Bolognese L. Comparison of intravenous urokinase plus heparin versus heparin alone in acute myocardial infarction. Urochinasi per via Sistemica nell'Infarto Miocardico (USIM) Collaborative Group. Am J Cardiol. 1991;68(6):585-92. https:// doi.org/10.1016/0002-9149(91)90348-o.

8. Group ISAMS. A prospective trial of intravenous streptokinase in acute myocardial infarction (I.S.A.M.). Mortality, morbidity, and infarct size at 21 days. N Engl J Med. 1986;314(23):1465-71. https://doi.org/10.1056/NEJM198606053142301.

9. Effect of intravenous APSAC on mortality after acute myocardial infarction: preliminary report of a placebo-controlled clinical trial. AIMS Trial Study Group. Lancet. 1988;1(8585):545-9.

10. Wilcox RG, von der Lippe G, Olsson CG, Jensen G, Skene AM, Hampton JR. Trial of tissue plasminogen activator for mortality reduction in acute myocardial infarction. Anglo-Scandinavian Study of Early Thrombolysis (ASSET). Lancet. 1988;2(8610): 525-30. https://doi.org/10.1016/s0140-6736(88)92656-6.

11. Randomised trial of late thrombolysis in patients with suspected acute myocardial infarction. EMERAS (Estudio Multicentrico Estreptoquinasa Republicas de America del Sur) Collaborative Group. Lancet. 1993;342(8874):767-72.

12. Late Assessment of Thrombolytic Efficacy (LATE) study with alteplase 6-24 hours after onset of acute myocardial infarction. Lancet. 1993;342(8874):759-66.

13. Indications for fibrinolytic therapy in suspected acute myocardial infarction: collaborative overview of early mortality and major morbidity results from all randomised trials of more than 1000 patients. Fibrinolytic Therapy Trialists' (FTT) Collaborative Group. Lancet. 1994;343(8893):311-22.

14. Ellis CJ, French JK, White HD. Is thrombolytic therapy really better than conventional treatment in acute inferior myocardial infarction? Br Heart J. 1995;74(4):476-7 author reply 7-8.

15. Bode C, Smalling RW, Berg G, Burnett C, Lorch G, Kalbfleisch $\mathrm{JM}$, et al. Randomized comparison of coronary thrombolysis achieved with double-bolus reteplase (recombinant plasminogen activator) and front-loaded, accelerated alteplase (recombinant tissue plasminogen activator) in patients with acute myocardial infarction. The RAPID II Investigators Circulation. 1996;94(5):891-8. https://doi.org/10.1161/01.cir.94.5.891.

16. Llevadot J, Giugliano RP, Antman EM. Bolus fibrinolytic therapy in acute myocardial infarction. JAMA. 2001;286(4):442-9. https:// doi.org/10.1001/jama.286.4.442.

17. Armstrong PW, Gershlick AH, Goldstein P, Wilcox R, Danays T, Lambert Y, et al. Fibrinolysis or primary PCI in ST-segment elevation myocardial infarction. N Engl J Med. 2013;368(15):1379-87. https://doi.org/10.1056/NEJMoa1301092.

18. Pinto DS, Frederick PD, Chakrabarti AK, Kirtane AJ, Ullman E, Dejam A, et al. Benefit of transferring ST-segment-elevation myocardial infarction patients for percutaneous coronary intervention compared with administration of onsite fibrinolytic declines as delays increase. Circulation. 2011;124(23):2512-21. https://doi.org/ 10.1161/CIRCULATIONAHA.111.018549.

19. Pinto DS, Kirtane AJ, Nallamothu BK, Murphy SA, Cohen DJ, Laham RJ, et al. Hospital delays in reperfusion for ST-elevation myocardial infarction: implications when selecting a reperfusion strategy. Circulation. 2006;114(19):2019-25. https://doi.org/10. 1161/CIRCULATIONAHA.106.638353. 
20. Grines CL, Browne KF, Marco J, Rothbaum D, Stone GW, O'Keefe J, et al. A comparison of immediate angioplasty with thrombolytic therapy for acute myocardial infarction. The Primary Angioplasty in Myocardial Infarction Study Group. N Eng1 J Med. 1993;328(10):673-9. https://doi.org/10.1056/ NEJM199303113281001.

21. Nunn CM, O'Neill WW, Rothbaum D, Stone GW, O'Keefe J, Overlie P, et al. Long-term outcome after primary angioplasty: report from the primary angioplasty in myocardial infarction (PAMII) trial. J Am Coll Cardiol. 1999;33(3):640-6. https://doi.org/10. 1016/s0735-1097(98)00622-6.

22. Global Use of Strategies to Open Occluded Coronary Arteries in Acute Coronary Syndromes Angioplasty Substudy I. A clinical trial comparing primary coronary angioplasty with tissue plasminogen activator for acute myocardial infarction. N Engl J Med. 1997;336(23):1621-8. doi:https://doi.org/10.1056/ NEJM199706053362301.

23. Zahn R, Koch A, Rustige J, Schiele R, Wirtzfeld A, Neuhaus KL, et al. Primary angioplasty versus thrombolysis in the treatment of acute myocardial infarction. ALKK Study Group Am J Cardiol. 1997;79(3):264-9. https://doi.org/10.1016/s0002-9149(96)00745$\mathrm{x}$.

24. Bonnefoy E, Lapostolle F, Leizorovicz A, Steg G, McFadden EP, Dubien PY, et al. Primary angioplasty versus prehospital fibrinolysis in acute myocardial infarction: a randomised study. Lancet. 2002;360(9336):825-9. https://doi.org/10.1016/S0140-6736(02) 09963-4.

25. Aversano T, Aversano LT, Passamani E, Knatterud GL, Terrin ML, Williams DO, et al. Thrombolytic therapy vs primary percutaneous coronary intervention for myocardial infarction in patients presenting to hospitals without on-site cardiac surgery: a randomized controlled trial. JAMA. 2002;287(15):1943-51. https://doi.org/10. 1001/jama.287.15.1943.

26. Thiele H, Scholz M, Engelmann L, Storch WH, Hartmann A, Dimmel G, et al. ST-segment recovery and prognosis in patients with ST-elevation myocardial infarction reperfused by prehospital combination fibrinolysis, prehospital initiated facilitated percutaneous coronary intervention, or primary percutaneous coronary intervention. Am J Cardiol. 2006;98(9):1132-9. https://doi.org/10. 1016/j.amjcard.2006.05.044.

27. Widimsky P, Groch L, Zelizko M, Aschermann M, Bednar F, Suryapranata H. Multicentre randomized trial comparing transport to primary angioplasty vs immediate thrombolysis vs combined strategy for patients with acute myocardial infarction presenting to a community hospital without a catheterization laboratory. The PRAGUE study Eur Heart J. 2000;21(10):823-31. https://doi.org/ 10.1053/euhj.1999.1993.

28. Armstrong PW, Committee WS. A comparison of pharmacologic therapy with/without timely coronary intervention vs. primary percutaneous intervention early after ST-elevation myocardial infarction: the WEST (Which Early ST-elevation myocardial infarction Therapy) study. Eur Heart J. 2006;27(13):1530-8. https://doi.org/ 10.1093/eurheartj/ehl088.

29. Andersen HR, Nielsen TT, Rasmussen K, Thuesen L, Kelbaek H, Thayssen $\mathrm{P}$, et al. A comparison of coronary angioplasty with fibrinolytic therapy in acute myocardial infarction. N Engl J Med. 2003;349(8):733-42. https://doi.org/10.1056/NEJMoa025142.

30. Di Mario C, Dudek D, Piscione F, Mielecki W, Savonitto S, Murena E, et al. Immediate angioplasty versus standard therapy with rescue angioplasty after thrombolysis in the Combined Abciximab REteplase Stent Study in Acute Myocardial Infarction (CARESS-in-AMI): an open, prospective, randomised, multicentre trial. Lancet. 2008;371(9612):559-68. https://doi.org/10.1016/ S0140-6736(08)60268-8.

31. Dobrzycki S, Kralisz P, Nowak K, Prokopczuk P, Kochman W, Korecki J, et al. Transfer with GP IIb/IIIa inhibitor tirofiban for primary percutaneous coronary intervention vs. on-site thrombolysis in patients with ST-elevation myocardial infarction (STEMI): a randomized open-label study for patients admitted to community hospitals. Eur Heart J. 2007;28(20):2438-48. https://doi.org/10. 1093/eurheartj/ehm369.

32. Boersma E. Primary coronary angioplasty vs. thrombolysis G. does time matter? A pooled analysis of randomized clinical trials comparing primary percutaneous coronary intervention and in-hospital fibrinolysis in acute myocardial infarction patients. Eur Heart J. 2006;27(7):779-88. https://doi.org/10.1093/eurheartj/ehi810.

33. Berger PB, Ryan TJ. Inferior myocardial infarction. High-risk subgroups. Circulation. 1990;81(2):401-11. https://doi.org/10.1161/ 01.cir.81.2.401.

34. Hasdai D, Sclarovsky S, Solodky A, Sulkes J, Birnbaum Y. Prognostic significance of the initial electrocardiographic pattern in patients with inferior wall acute myocardial infarction. Clin Cardiol. 1996;19(1):31-6. https://doi.org/10.1002/clc. 4960190107.

35. Birnbaum Y, Herz I, Sclarovsky S, Zlotikamien B, Chetrit A, Olmer L, et al. Prognostic significance of precordial ST segment depression on admission electrocardiogram in patients with inferior wall myocardial infarction. J Am Coll Cardiol. 1996;28(2):313-8. https://doi.org/10.1016/0735-1097(96)00173-8.

36. Hasdai D, Birnbaum Y, Porter A, Sclarovsky S. Maximal precordial ST-segment depression in leads V4-V6 in patients with inferior wall acute myocardial infarction indicates coronary artery disease involving the left anterior descending coronary artery system. Int J Cardiol. 1997;58(3):273-8. https://doi.org/10.1016/s01675273(96)02881-1.

37. Mager A, Sclarovsky S, Herz I, Adler Y, Strasberg B, Birnbaum Y. Value of the initial electrocardiogram in patients with inferior-wall acute myocardial infarction for prediction of multivessel coronary artery disease. Coron Artery Dis. 2000;11(5):415-20. https://doi. org/10.1097/00019501-200007000-00006.

38. Lee HS. Is thrombolytic therapy really better than conventional treatment in acute inferior myocardial infarction? Br Heart J. 1995;74(4):476; author reply 7-8-8.

39. Tobe TJ. Is thrombolytic therapy in acute inferior myocardial infarction really better than conventional treatment? Br Heart J. 1995;73(2):108-9. https://doi.org/10.1136/hrt.73.2.108.

Publisher's Note Springer Nature remains neutral with regard to jurisdictional claims in published maps and institutional affiliations. 